\title{
ENSAIO ÉTICO-FILOSÓFICO ACERCA DOS FUNDAMENTOS DA JUSTIÇA RESTAURATIVA
}

\author{
ETHICAL-PHILOSOPHICAL ESSAY ON THE FOUNDATIONS OF \\ RESTORATIVE JUSTICE
}

Recebido: 26.05.2019

\begin{abstract}
Selma Pereira De Santana
Doutora em Direito pela Universidade de Coimbra. Professora adjunta de Direito Penal da Faculdade de Direito da Universidade Federal da Bahia Membro do Ministério Público Militar da União.

EMAIL: selmadesantana@gmail.com

LATTES: http:/ / lattes.cnpq.br/9229440571677571

ORCID: https://orcid.org/0000-0002-2597-4595
\end{abstract}

Aprovado: 28.03.2020

\author{
Belmiro Vivaldo Santana Fernandes \\ Doutorando em Direito pela Universidade Federal da \\ Bahia. Professor da União Metropolitana de Educação \\ e Cultura (UNIME). Advogado e Juiz Leigo do \\ Tribunal de Justiça do Estado da Bahia. \\ EMAIL: belmirofernandes@gmail.com \\ LATTES: http:/ / lattes.cnpq.br/9229440571677571 \\ ORCID: https://orcid.org/0000-0002-6777-6167
}

RESUMO: O reconhecimento da justiça restaurativa como instituição legítima para proporcionar uma resposta adequada à solução de litígios, especialmente de origem penal, ainda representa muitos desafios, inclusive dentre os seus defensores. No modelo restaurativo uma forma diferenciada de responder ao crime, adotando práticas que reconheçam o caráter interpessoal do conflito, o que ocorrerá através da pacificação social por meio da reparação de danos causados à vítima e da auto responsabilização do agente infrator. Tal propósito apenas poderá ser atingido se for reconhecida a autonomia dos participantes do litígio, superando o papel da vítima como mero objeto de prova e do Estado como o único titular da persecução penal. Neste sentido, faz-se necessário visitar o pensamento de pensadores éticos e jurídicos que compreendam como a cultura e os valores da vulnerabilidade e da alteridade são imprescindíveis para uma mais adequada aplicação da justiça restaurativa como instituto complementar e paralelo da justiça retributiva. O presente artigo utilizou-se do método teóricodescritivo, através de revisão de literatura, com viés essencialmente crítico-filosófico. Por fim, compreendemos que a justiça restaurativa é ferramenta legítima para o enfrentamento dos conflitos penais e assemelhados, visto que a mesma encontra base em diversos modelos crítico filosóficos, que apenas necessitam ser resgatados.

PALAVRAS-CHAVE: justiça restaurativa; culturalismo; ética; alteridade

\begin{abstract}
The recognition of restorative justice as a legitimate institution to provide an adequate response to the dispute settlement, especially of criminal origin, still poses many challenges, including among its defenders. In the restorative model a differentiated form of responding to crime, adopting practices that recognize the interpersonal character of the conflict, which will occur through social pacification through the reparation of damage caused to the victim and self-accountability of the Infringing agent. This purpose can only be achieved if the autonomy of the participants of the dispute is acknowledged, overcoming the role of the victim as a mere object of proof and of the state as the sole holder of the criminal prosecution. In this sense, it is necessary to visit the thought of ethical and legal thinkers who understand how the culture and values of vulnerability and otherness are indispensable for a more appropriate
\end{abstract}


application of restorative justice as an institute Complementary and parallel of restributive justice. This article used the theoretical-descriptive method, through a literature review, with essentially critical-philosophical bias. Finally, we understand that restorative justice is a legitimate tool for confronting criminal and similar conflicts, since it is based on several philosophical critical models, which only need to be redeemed.

KEYWORDS: restorative justice; culturalism; ethics; otherness

SUMÁRIO: 1 Introdução $2 \mathrm{O}$ tratamento ético da vulnerabilidade e da alteridade $3 \mathrm{O}$ paradigma pluralista na bioética e o princípio da permissão: um diálogo com Hugo Tristam Engelhardt 4 A cultura e o ordenamento jurídico 5 Finalidades da pena 6 Do paradigma retributivo para o restaurativo 7 Considerações finais 8 Referências

\section{Introdução}

O reconhecimento da justiça restaurativa como instituição legítima para proporcionar uma resposta adequada à solução de litígios, especialmente de origem penal, ainda representa muitos desafios, inclusive dentre os seus defensores. A superação do punitivismo e da justiça dita "tradicional e formal" é objeto de resistência por parte dos teóricos mais conservadores, que ainda estão baseados em um modelo no qual o Estado detém o monopólio do poder de persecução e de aplicação da pena.

Por outro lado, tem-se no modelo restaurativo uma forma diferenciada de responder ao crime, adotando práticas que reconheçam o caráter interpessoal do conflito, o que ocorrerá através da pacificação social por meio da reparação de danos causados à vítima e da auto responsabilização do agente infrator. Tal propósito apenas poderá ser atingido se for reconhecida a autonomia dos participantes do litígio, superando o papel da vítima como mero objeto de prova e do Estado como o único titular da persecução penal.

Nesta rota de empoderamento e iluminação dos participantes do conflito, faz-se necessário o reconhecimento da vulnerabilidade não apenas da vítima, como do próprio sujeito do delito, visto que se trata de uma decorrência da própria condição humana. Soma-se a isto o próprio reconhecimento da alteridade enquanto valor ético fundamental para o enxergar o outro com suas próprias características; não se tentando buscar semelhanças, mas respeitando-se as diferenças dentro de uma sociedade plural.

É neste sentido que se insere o pensamento de Tristam Engelhardt, pensador célebre da bioética, mas que construiu a teoria dos "estranhos morais", em que as partes, mesmo sem fazerem parte de um mesmo paradigma moral, podem e devem chegar a um acordo, ainda que não compartilhem dos mesmos valores.

Por fim, é preciso compreender que a mudança paradigmática da justiça retributiva para a restaurativa é cultural e, dentro deste prisma, cabe revisitar o pensamento de Emil Lask, citado por Miguel Reale, que trata de importantes intersecções entre o direito e a vida social - e seus valores o que representa importante fundamento para o paradigma que se pretende alcançar.

O presente artigo utilizou-se do método teórico-descritivo, através de revisão de literatura, com viés essencialmente crítico-filosófico. Epistemologicamente, optou-se por não se adentrar nos mecanismos da justiça restaurativa, mas sim aos fundamentos crítico-filosóficos com os quais a mesma dialoga.

Em síntese, este trabalho representa uma humilde colaboração para o reconhecimento da justiça restaurativa como ferramenta legítima para o enfrentamento dos conflitos penais e 
assemelhados, visto que a mesma encontra base em diversos modelos crítico filosóficos, como adiante exposto.

\section{0 tratamento ético da vulnerabilidade e da alteridade}

A categoria da vulnerabilidade aparece na obra madura de Emmanuel Lévinas, tendo seu primeiro desenvolvimento em "Humanismo do outro homem" (1972), para um aprofundamento mais exaustivo em "De outro modo que o ser além de sua essência" (1974) ${ }^{1}$.

A vulnerabilidade é apresentada como a sensibilidade corporal da subjetividade, anterior à consciência, manifestada na proximidade do contato com o outro, pela qual alguém pode ser afetado e transformado em um sujeito ético, a partir do mandado do rosto do outro, de quem deve responder em sua fome e desnudez, inteligência e clamor, convertendo-se em um eleito para dar resposta. Revelam-se como palavras-chave: "vulnerabilidade", "sensibilidade", "contato", "proximidade", "passividade originária", além de outros, como "obrigação irrecusável", "obsessão", "traumatismo" e "refém"

Com o conceito de vulnerabilidade, o autor desenvolve a questão chave de sua obra, ao colocar a sensibilidade como fundamento da ética, produzindo um giro ético diante de seus antecessores filosóficos, como Husserl e Heidegger, além da própria filosofia ocidental. A característica marcante de Lévinas é a da produção de uma moral não intelectualista, cuja origem e embasamento é a sensibilidade corporal, e não a consciência da razão ou deliberação racional da liberdade ${ }^{3}$.

Para Lévinas, o sujeito não se descreve a partir da intencionalidade própria da atividade representativa, da objetivação, da liberdade e da vontade, mas sim a partir da passividade do tempo ${ }^{4}$.

A relação ética de Lévinas é originada por uma afetação de sensibilidade, a partir da proximidade e do contato sensível e carnal frente à demanda do outro. A revelação do outro provoca uma radical inversão da intencionalidade do conhecimento objetivo, pois ocorre em uma não consciência intencional, com o contato da sensibilidade afetada pelo rosto do outro ${ }^{6}$

Desta sensibilidade afetada pelo rosto do outro, surge a alteridade e a responsabilidade como decorrência do "outro-em-si-mesmo". A relação com o outro, com o próximo, cumpre-se com o dizer, que significa "responder ao outro" ${ }^{5}$.

$\mathrm{Na}$ ética levinasiana, há a afetação corporal com a carne, provocada com a proximidade e contato com a alteridade, do estranho ou exterior a si mesmo, que adentra desde fora, e, consequentemente, constitui passivamente um sujeito ético que deve responder o outro antes que tenha uma consciência reflexiva de sê-lo ${ }^{6}$.

\footnotetext{
${ }^{1}$ PALACIO, M. La vulnerabilidad fundando lá ética de la solidaridad y la justicia. Análisis. Revista de Investigación filosófica, v. 2, n. 1, p. $29-47,2015$.

${ }^{2}$ Ibid.

${ }^{3}$ CHALIER, C. Por una moral más allá del saber. Kant y Lévinas. Madri: Caparrós, 2002.

${ }^{4}$ LÉVINAS, E. Autrement qu'être ou au-dela de l'essence. Haia: The Hague: Martinus Nihjoff, 1978. p. $108^{6}$

DAVIS, C. Levinas - An Introduction. Indiana - EUA: University of Notre Dame Press, 1996.

${ }^{5}$ LÉVINAS, op. cit., p. 99

${ }^{6}$ CARDO, J. L. Lévinas - El sujeto debe responsabilizarse de los otros hasta el punto de renunciar a sí mismo. Barcelona: RBA Contenidos Editoriales y Audiovisuales, 2015. p. 99

7 | Revista do Programa de Pós-Graduação em Direito da UFBA, e-issn 2358-4777, v. 30, n. 01, p.05-24, Jan-Jun 2020
} 
O sujeito é, para Lévinas, sensibilidade, porque está aberto ao outro, anteriormente a um ato de consciência ou representação. E, assim, Lévinas já define esta relação através de três termos: subjetividade, sensibilidade e vulnerabilidade ${ }^{7}$.

Para Lévinas, a vulnerabilidade é a fissão da identidade do eu, por uma demanda e responsabilidade, anterior à consciência reflexiva. O clamor do outro é um rosto nu. A vulnerabilidade do sujeito é dada por sua sensibilidade, ou exposição ao ultraje e à ferida, uma passividade mais passiva que qualquer paciência ${ }^{8}$. Ao mesmo tempo, a subjetividade deve ser entendida como uma substituição do outro, uma expiação ${ }^{9}$.

Com esta passividade radical, o sujeito é responsável em anterioridade à eleição de sua liberdade. Trata-se de uma doação, sacrifício sem reservas, elegendo o bem de forma involuntária.

Ser vulnerável, portanto, é estar exposto e haver-sido-oferecido, que é uma experiência sensível e encarnada do corpo onde se tem a relação ética, com ligação de responsabilidade irrecusável com o outro. Logo, a subjetividade é constituída pelo outro com um fundo de substituição ética ${ }^{10}$.

Com o giro radical do pensamento de Lévinas em respeito a outros preceitos éticos tradicionais, existe a compreensão do sofrimento do outro, passível de responsabilidade. Com a aproximação da vulnerabilidade ou sensibilidade da carne exposta (vulnerabilidade do sujeito, o outro irrompe como um rosto vulnerável e desnudo (vulnerabilidade da alteridade), exigindo e clamando por uma responsabilidade, por uma resposta irrecusável que nos converte em seres únicos e eleitos.

A partir das leituras levinasianas e assumindo sua posição de que a vulnerabilidade é um dom e pura gratuidade involuntária de um para o outro, é possível afirmar que a vulnerabilidade é o fundamento e origem da lógica da solidariedade, porque somente um ser animado, e, assim, vulnerável, pode oferecer-se e doar-se para o outro. Assim, a subjetividade é a expressão de si mesmo para o outro, desinteressado, em uma relação não recíproca ou assimétrica ${ }^{11}$.

Para Lévinas, a subjetividade é a vulnerabilidade que responde, sendo responsável pelo outro. O próprio Lévinas indica que a condição de toda a solidariedade possível é dada porque o sujeito é refém, é quem suporta passivamente a chamada do outro, que não tem alternativa entre a atividade ou a passividade. Diz, portanto, que o "eu" é solidário com o outro antes mesmo ter de assim decidido, pois o próximo interessa antes de qualquer compromisso consentido ou rechaçado, sem qualquer relação contratada ${ }^{12}$.

A própria vulnerabilidade pode ser considerada a lógica da justiça, alijada no nível do discurso e da razão, esferas estas que adquirem sentido na proximidade sensível da vulnerabilidade, constituindo a responsabilidade irrecusável que obriga a cada um. Entretanto, a responsabilidade não somente vincula o próximo, mas também o terceiro, que é o "próximo do outro", e não apenas o próprio semelhante ${ }^{13}$.

Neste sentido, o fundamento da obrigação jurídica do Estado e da lei racional não se baseia apenas na razão ou na liberdade delegada - muito menos no estado de guerra ou da natureza, conforme Hobbes - mas se enraíza na vulnerabilidade, na sensibilidade e na subjetividade. Com o terceiro nasce a questão da justiça como pressuposto de consciência. E o que deve ser feito com a

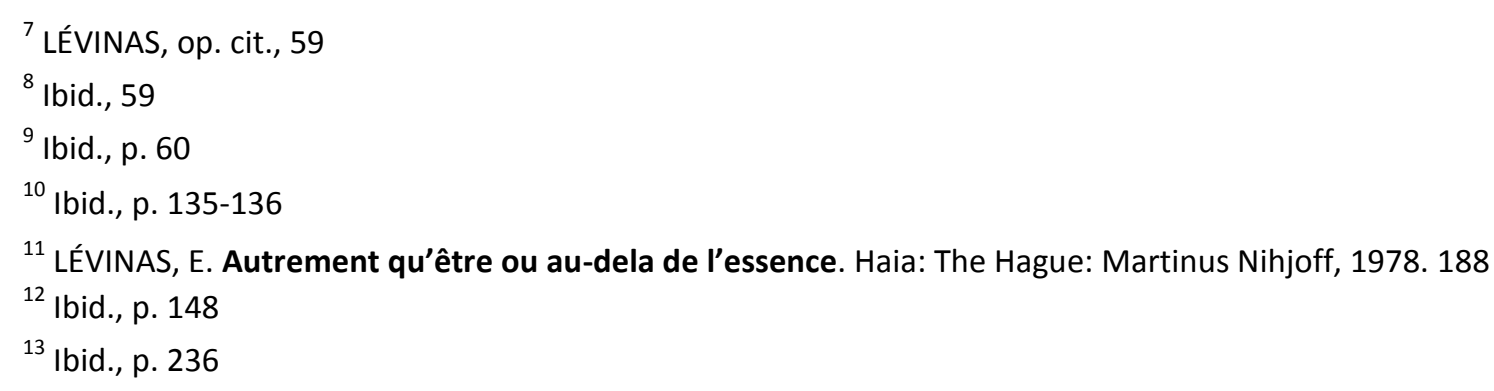

8 | Revista do Programa de Pós-Graduação em Direito da UFBA, e-issn 2358-4777, v. 30, n. 01, p.05-24, Jan-Jun 2020 
justiça? Para Lévinas, a esfera normativa da existência mostra-se imperfeita em expressar sua radicalidade na obrigação ética frente à alteridade absoluta do outro ${ }^{14}$.

Apesar das instituições da justiça serem necessárias, mostram-se secundárias diante do mandato original relativo à sensibilidade do sujeito. Respondem à necessidade de compreender e dar inteligibilidade às ações entre os homens e a normatizar a reciprocidade. Far-se-ia necessária uma copresença, em pé de igualdade, como diante de uma corte de justiça ${ }^{17}$.

Se na relação ética da solidariedade com o outro há diacronia e assimetria, na esfera normativa da justiça positiva deve haver, ao contrário, sincronia e reciprocidade. Em última instância, o fundamento da responsabilidade irrecusável diante do outro é a bondade. A obsessão clama pela justiça, reclama medida e tem consciência ${ }^{15}$.

Neste sentido, a solidariedade seria anterior e superior à justiça, porque ocorre no tempo imemorial da sensibilidade, do corpo exposto, da significação pré-originária da linguagem e do dizer. É o fundamento ético original e a responsabilidade que se produz na subjetividade antes da consciência reflexiva e que, na liberdade, se realizem os atos ${ }^{16}$.

De certo modo, o que Lévinas ensina é que antes de se agir pela razão e estratégia, deve-se deixar levar pelo impulso ético da emoção e da afeição da própria vulnerabilidade, que provoca o rosto nu do outro, sendo um acontecimento pré-originário à consciência reflexiva. Com a emoção sensível da vulnerabilidade, se produz o fundamento ético, que verterá na possibilidade de liberdade, onde se dá o início da justiça para remediar o processo de exclusão e de vulnerabilidade progressiva do outro, diante da lógica do egoísmo ${ }^{17}$.

A partir daqui é possível refletir em uma lógica da justiça, em que sejam instituídas leis que possam garantir a proteção dos mais vulneráveis da sociedade, mas cuja qualidade de justiça não advenha meramente de sua legalidade, mas porque se apoia em um fundamento ético anterior e pré-originário da subjetividade, semelhante ao próprio psiquismo do corpo maternal ${ }^{18}$.

A justiça é um momento posterior e necessário para equilibrar os conflitos de interesses entre os sujeitos egoístas que delegam racionalmente ao Estado a preservação da paz, a fim de regular e limitar a arbitrariedade da liberdade, que é sedutora por se tratar de um poder, de essência, assassino do outro, representando uma força centrípeta e egológica de si mesmo ${ }^{19}$.

Com o sistema levinasiano, é possível construir processos de inclusão baseados na lógica da solidariedade e da justiça, legitimando ações solidárias (ajudas, colaboração, subsídios, doação), bem como ações de justiça (como ações positivas em face de grupos desfavorecidos social e historicamente), cujas sendas de justificação e fundamentação residem na vulnerabilidade da própria subjetividade, e de onde a responsabilidade é irrecusável para cada um.

Isto implica uma inversão de precedência de conceitos clássicos de justiça e solidariedade, pois a justiça passa a ser a ação primária ética diante dos outros, e a solidariedade se concebe originando as ações não obrigatórias, além da norma. Pelo contrário, com Lévinas, primeiro se fala na solidariedade como obrigação ética da responsabilidade pelo outro porque a "minha subjetividade vulnerável é constituída do desmembramento do outro", já que eu sou "o outro em mim mesmo" 20 .

\footnotetext{
${ }^{14}$ LÉVINAS, op. cit., p. 236

${ }^{15}$ Ibid., p. 236

${ }^{16}$ LÉVINAS, E. Autrement qu'être ou au-dela de l'essence. Haia: The Hague: Martinus Nihjoff, 1978. p. 48

${ }^{17}$ Ibid., p. 56

18 Ibid., p. 124

${ }^{19}$ LÉVINAS, E. Totalidade e infinito. Lisboa: Edições 70, 2008. p. 71

${ }^{20}$ LÉVINAS, op. cit., p. 72
}

9 | Revista do Programa de Pós-Graduação em Direito da UFBA, e-issn 2358-4777, v. 30, n. 01, p.05-24, Jan-Jun 2020 
Em uma segunda instância está a justiça como ordenamento normativo, como garantia legal e obrigação positiva imprescindível para preservar o desvio arbitrário da liberdade e seu consentimento na vontade do poder, que pode resvalar na eliminação daquele que se contrapõe aos interesses de quem está no poder, como, diversas vezes, a própria história traz diversas amostras.

\section{0 paradigma pluralista na bioética e o princípio da permissão: um diálogo com Hugo Tristam Engelhardt}

O ponto de partida do pensamento de Tristam Engelhardt para a questão bioética é empírico, pois entende que não existe uma moral com conteúdo puramente universal. Assim, uma "moral de conteúdo" ou "material" é aquela que entrega orientação sobre o que é bom ou mau e propõe condutas corretas ao indivíduo, especialmente em seu dever de não causar danos a terceiros. Por outro lado, a moral procedimental, pelo contrário, refere-se somente à viabilidade formal ou empírica da norma, que visa fundamentar-se através do estabelecimento de instâncias processuais. Logo, uma ética que serve de paradigma para outros casos concretos será uma ética de caráter material $^{21}$.

A moral universal, por sua vez, é aquela que se aplica a todas as pessoas, em todos os lugares. A ideia de universalidade de Engelhardt é contratualista, pois pressupõe que os grupos humanos aceitem determinado conteúdo. Entretanto, reconhece que há um fracasso moderno em que sejam reconhecidos por todos os bens em caráter universal. Assim, a universalidade não tem, em verdade, um conteúdo substantivo, consistindo, simplesmente, no alcance de um acordo, consistindo tão-somente em uma ética e uma bioética puramente formais. Engelhardt não busca uma compreensão tão ampla como no pós-estruturalismo, mas compartilha da ideia de haver um caráter fragmentário das regras, assim como a própria impossibilidade de se retroceder a uma situação como a qual, que denomina o "tempo das grandes narrações"22.

A discussão de Engelhardt se dá com os autores contratualistas e liberais, muito mais do que com autores do realismo clássico, como se levaria a concluir a partir de sua formação católica, a exemplo de Santo Tomás de Aquino e com a Escola de Direito Natural ${ }^{23}$.

Engelhardt estima que, uma vez a síntese cristã começa a se debilitar, o impulso moderno não busca transferir o sentido da ética clássica, mas sim garantir a essência da autoridade moral em um mondo em que o Renascimento perdia sua força cultural, a partir dos acontecimentos históricos daquele determinado momento, e a criação de seus paradigmas filosóficos. Por isto, afirma que a redistribuição dos interesses culturais em torno da saúde e da postergação da morte estão relacionados ao fundamento do pensamento moderno que surgiu com o Renascimento e a Reforma, tendo havido o rompimento com a unidade religiosa do Cristianismo Ocidental ${ }^{24}$.

A visão cristã tradicional do mundo teve de se enfrentar com um fanatismo religioso dividido entre numerosas religiões e as atrações de um humanismo imanente. $O$ crescente interesse pelo estudo das humanidades havia desbancado o estudo do divino. Assim, era pujante a busca da essência da razão em postular princípios que fossem universais, categóricos e internamente consistentes e, portanto, a moral racional postulará princípios que tenham condições

\footnotetext{
${ }^{21}$ MADRID, R. La bioética de Tristram Engelhardt: entre la contradicción y la postmodernidad. Revista Bioética, Pontificia Universidad Católica de Chile, Santiago, v. 22, n. 3, p. 441 - 447, 2014. Disponível em: <http://www. scielo.br/scielo.php?script=sci_arttext\&pid=S1983-80422014000300007\&lng=es\&t|ng=es>. Acesso em: 25 nov 2018. p. 442

22 Ibid., 442.

${ }^{23}$ MADRID, R. op. cit. 443

${ }^{24}$ Ibid., 442
}

10 | Revista do Programa de Pós-Graduação em Direito da UFBA, e-issn 2358-4777, v. 30, n. 01, p.05-24, Jan-Jun 2020 
de serem mantidos por todas as pessoas, independente de circunstâncias e condições, que possam ser obedecidos invariavelmente por qualquer agente racional, em qualquer ocasião ${ }^{25}$.

Como resultado, assim como sabido, houve mais adversidades do que a consagração deste ideal. O vazio deixado pela perda da unidade da fé e da razão dos pensadores católicos não foi seguido por um programa secular de racionalidade moral que conclamou um acordo de um mundo progressivamente mais amplo e diverso, mas sim uma situação diversa: se a unidade do pensamento sobre a vida iria ser alcançado através da filosofia, a supressão dos cânones católicos gerou a multiplicação de filosofias opostas, também no âmbito moral. Isto, segundo Engelhardt, é justamente o elemento que definirá a pós-modernidade.

Mais que a unidade do Espírito, havia dissidência e discordância; mais que uma harmonia das convenções, produziam-se disputas na diversidade. Sua tese é que, apesar de tal diversidade parecer ser fruto de forças históricas um tanto quanto recentes, não eram verdadeiramente novas, porque estavam de certa maneira, ocultas dentro da própria sociedade. Por isto, afirma que "a diversidade moral é acompanhada desde os primeiros registros da história" ${ }^{26}$.

A causa desta circunstância não é, para Engelhardt, uma certa determinação interna do ser humano, das sociedades ou da história, como se poderia encontrar em outros pensadores, a exemplo de Derrida, mas, simplesmente, o ganho de complexidade e o tamanho das comunidades em que tal fenômeno se produz ${ }^{27}$.

Logo, para modelar uma sociedade que não seja pluralista, quase que seguramente haveria de se construir uma sociedade de escala muito reduzida, provavelmente não muito maior do que uma Cidade-Estado grega, pois a visão de polis de Aristóteles tem influenciado sobremaneira o Ocidente e, indiretamente, o resto do mundo, não passando de uma pequena cidade que não recepcionava, de bom grado, seus imigrantes, para que não pudesse romper com sua unidade cultural.

O eixo constitutivo da pós-modernidade é, para tanto, o da diversidade. Não se trata de uma diversidade que deva ser corrigida, mas uma realidade que deve conseguir se fazer operacional, prática. Não há de se perder de vista a inspiração prática da análise de Engelhardt, cuja preocupação final é abordar corretamente problemas concretos da bioética e da medicina contemporâneas; não a proporcionar uma explicação teórica a problemas filosóficos ${ }^{28}$.

Enquanto a modernidade buscava um tipo de moral material - ou dotada de conteúdo - a pós-modernidade se satisfaz com o paradigma da mera diferença. Engelhardt, assim, aponta que nos últimos anos tem havido uma maior aceitação de tais diferenças do que se imaginou em todo um passado. Assim, desenvolveu-se uma ampla e bem articulada coalizão de diferentes tendências permissivas, sem desconsiderar a evidência de profundos desacordos, muitas vezes entrelaçados com outros desacordos. O dito projeto moderno abarca, portanto, diversas comunidades religiosas ou ideológicas, na medida em que existia a esperança de se encontrar uma concepção concreta da justiça e da ação moralmente correta que expressariam e traduziriam as exigências da racionalidade e da humanidade. Cabe destacar o especial significado que tem a concepção de "ideologia", pela qual se entende como uma tradução secular da religião, ao consistir uma concatenação de ideias, imagens, valores morais, pressupostos metafísicos e epistemológicos que proporcionam a um

\footnotetext{
${ }^{25}$ ENGELHARDT, J. H. T. Fundamentos da Bioética. 5. ed. São Paulo: Edições Loyola, 2013. p. 89

${ }^{26}$ Ibid., p. 110

${ }^{27}$ MADRID, R. La bioética de Tristram Engelhardt: entre la contradicción y la postmodernidad. Revista Bioética, Pontificia Universidad Católica de Chile, Santiago, v. 22, n. 3, p. 441 - 447, 2014. Disponível em: <http://www. scielo.br/scielo.php?script=sci_arttext\&pid=S1983-80422014000300007\&lng=es\&t|ng=es>. Acesso em: 25 nov 2018. p. 445

${ }^{28}$ Ibid. p. 446
}

11 | Revista do Programa de Pós-Graduação em Direito da UFBA, e-issn 2358-4777, v. 30, n. 01, p.05-24, Jan-Jun 2020 
conjunto de pessoas uma concepção da moralidade, da justiça, das estruturas sociais adequadas e da autoridade política legítima ${ }^{29}$.

Engelhardt sustenta que, no período pós-moderno, muitos autores e intelectuais parecem não se darem conta da instalação da diferença como elemento focal das diversas linhas de pensamento. Assim, considera que a catástrofe fundamental da cultura contemporânea é o fracasso de encontrar uma moral secular canônica, dotada de conteúdo. Esta dicotomia parece responder a uma atitude igualmente pós-moderna do autor: uma coisa é reconhecer a existência da mentalidade diferencial própria do tempo contemporâneo; outra é concluir que o que se crê por fé (ou moral universal e única) não é possível pelos meios naturais, de modo que o natural se expressa pela diferença. Entretanto, segue-se simultaneamente crendo no cânone de um modo correto ideal e abstrato, em oposição aos bens pessoais e privados ${ }^{30}$.

Engelhardt reconhece a inconsequência, própria de uma mentalidade baseada exclusivamente na diferença, chegando a aceitar o argumento de que existiria uma impossibilidade cultural de uma lei moral de conteúdo universal, à qual qualifica, finalmente, como sectária (o conteúdo moral que separa e censura). No fundo, Engelhardt considera que toda a concepção material da moral é ideológica quando se pretende universalizar-se. Neste ponto, é oportuno comparar seu pensamento com o de Kant, que enfrenta, em seu momento, uma problemática parecida, mas que desenvolve solução mais harmoniosa e desenvolvida que a proposta por Engelhardt.

Dada a realidade inevitável do pluralismo imperativo do mundo contemporâneo, e a limitada capacidade da racionalidade para resolver controvérsias, a autoridade moral secular deve cercar-se de acordos concretos juntamente aos indivíduos e comunidades em particular, levando-os em consideração para as suas decisões. A intenção é proporcionar um marco pelo qual os indivíduos pertencentes das distintas comunidades morais possam se considerar vinculados por uma estrutura comum, colaborando uma a construção de uma ética global. Neste sentido, Engelhardt aceita os parâmetros pós-modernos da fragmentação e diversidade, mas se inclina a propor estruturas formais de acordo. Nota-se que não esse trata de um projeto de um pósmoderno, mas a reação de um moderno que se declara crente de uma realidade transcendental que é, em si mesma, fundamento de toda a moral, mas que termina cedendo a uma configuração de época para certos standards morais, aceitando, por assim dizer, as regras do jogo, que propõem aos inimigos de teses materiais.

\subsection{Os estranhos morais}

Engelhardt adverte uma condição para possibilitar a aplicação prática da teoria dos estranhos morais, que preside sua bioética: a necessidade de que exista uma sociedade pluralista secular pacífica, onde os estranhos tenham lugar e se encontrem ${ }^{31}$.

Denomina, deste modo, que as sociedades dispostas a aceitar as perspectivas morais diversas, de maneira que seus habitantes sejam em condições de expressar seus pontos de vista sem o temor de serem reprimidos e nem censurados. Para que ocorra a convivência na diversidade, deve-se haver um espaço, uma instância jurídica perfeitamente acreditada e certa.

Nesta linha, Engelhardt estabelece a distinção entre comunidade e sociedade. O primeiro conceito se refere a uma associação de indivíduos baseada em uma visão concreta, comum a todos eles, relativamente ao bem comum. Enquanto isto, a comunidade aponta as associações de

\footnotetext{
${ }^{29}$ ENGELHARDT, J. H. T. Fundamentos da Bioética. 5. ed. São Paulo: Edições Loyola, 2013. p. 135

30 . p.444

${ }^{31}$ MADRID, R. op. cit. p. 446
}

12 | Revista do Programa de Pós-Graduação em Direito da UFBA, e-issn 2358-4777, v. 30, n. 01, p.05-24, Jan-Jun 2020 
indivíduos que não compartilham da mesma visão comum de tal bem, mas que podem conseguir alcançar juntos um conjunto de objetivos importantes.

No interior das comunidades concretas onde se produzem as diversas possibilidades morais, tais problemas devem ser enfrentados na perspectiva da vida de pessoas reais. Como não existem argumentos seculares suficientes, para dirimir a maneira determinante do conflito entre as mais distintas visões (respeitando-se a visão do inocente), tais grupos são denominados estranhos morais.

Os estranhos morais têm de resolver suas diferenças por um mútuo acordo, já que não compartilham de uma moral de conteúdo, mas não significa que não possam chegar a um entendimento em absoluto. Para tanto, a primeira estratégia de colaboração, quando a verdade se converte em intersubjetividade - e, assim, se revela como múltipla - é reconhecer os procedimentos para trabalharem juntos sobre os desacordos morais e metafísicos. Esta estratégia oferece àqueles indivíduos separados por diferentes visões a possibilidade de obterem a autoridade não de Deus ou da razão, mas do acordo.

Em suas palavras: "A estranheza moral não exige que o outro seja incompreensivelmente diferente, mas tão somente que seja considerado como alguém diferente em virtude de possuir distintos compromissos morais ou metafísicos" ${ }^{\prime 2}$.

A compreensão de estranhos morais ocasiona um consistente arcabouço ético e bioético. Engelhardt reconhece que, apesar deste efeito, existe e permanece a aspiração da universalidade.

Porém, sua proposta busca uma moral que consiga se fazer presente, apesar do paradigma de existirem estranhos morais, e que tal moral possa se justificar no seio de diversas comunidades, ainda que estas se encontrem fundadas em diversas tradições, ideologias ou religiões.

Deste modo, a proposta de uma ética universal e canônica, de qualquer tipo que seja (substantiva ou processual), formula uma razão da existência dos estranhos morais; se todos fossem "amigos morais", não haveria semelhante empenho. A razão é que os estranhos têm relações entre si, e possuem obrigações que se fundam em tais vínculos. São pessoas que pertencem a diferentes culturas e crenças e que, por causa disto, carecem de conexão social, exceto pela certeza de que cada um quer seguir sua vida do modo que prefira, segundo seus interesses pessoais.

Nada há de comum entre os seres humanos, com exceção do empenho em seguir seus próprios interesses. Os indivíduos são os que autorizam ou permitem as estruturas sociais que se revelam como autorizativas, e por isto é que, segundo Engelhardt, a moral que vincula os "estranhos morais" tenderia ou deveria possuir um caráter inevitavelmente libertário, sendo uma consequência da impossibilidade de apoiar-se em autoridades transcendentes para formular as premissas e princípios morais, como Deus ou a razão objetiva.

Tal mecanismo de obter a autoridade moral através da aquiescência dos participantes da comunidade é o que Engelhardt denomina por "princípio da autoridade moral". Este princípio explica que, assim como Deus não é ouvido por todos da mesma maneira, nem todos pertencem a uma comunidade claramente definida e estreitamente unida, já que a razão fracassa no intento de se descobrir uma moral canônica dotada de conteúdo. Logo, a autorização ou autoridade moral justificada secularmente por um Deus não é a visão moral da comunidade, mas sim de alguns indivíduos dela pertencentes.

Para se que trate sobre as bases da cooperação entre tais indivíduos, os estranhos morais devem buscar uma estrutura neutra (ou alguma estrutura secular), de modo a se perceberem o que possuem em comum. Assim, cada um dirige sua vida de acordo com seus valores e bens pessoais, sem que a moral secular vá interferir a materialidade de suas crenças, mas tão-somente sua modulação baseada no acordo. Assim como afirmam, em geral, os libertários, Engelhardt não crê que se possa oferecer outra justificação de uma tida moral ou de sua fundamentação. Pelo

\footnotetext{
32 ENGELHARDT, J. H. T. Fundamentos da Bioética. 5. ed. São Paulo: Edições Loyola, 2013. 221
}

13 | Revista do Programa de Pós-Graduação em Direito da UFBA, e-issn 2358-4777, v. 30, n. 01, p.05-24, Jan-Jun 2020 
contrário, para ele, a única obrigação universal que a razão pode oferecer é aquela de respeitar estritamente a liberdade do outro.

Os estranhos morais são necessários para que se alcance a paz entre as pessoas, ao conseguir que as disputas e as diferenças entre as pessoas, de modo que se possa levar a um determinado processo de acordo que não vincule o ser material de um problema. Engelhardt aborda a questão da ética de um ângulo peculiar, deixando de lado o conteúdo substancial de uma ética universal, para que se interessar pelas condições de possibilidades de uma ética que permita uma convivência de perspectivas morais diferentes. Assim, a ética seria um modo de resolução das controvérsias no lugar da força, e se define como um empenho da resolução de conflitos de maneira não violenta ${ }^{33}$.

Por isto, é que sustenta que as diferenças entre as visões morais são reais e fundamentam concepções substancialmente diferentes, de tal modo que as controvérsias não se resolvem por meio exclusivo ou de argumentos racionais estritamente lógicos, ou à apelação de uma autoridade moral reconhecida por todos.

No fundo, a noção de estranhos morais supõe a afirmação da incapacidade estrutural da razão humana para discernir os bens morais em uma dimensão fundamental ou principal, priorizando uma compressão da formulação de aspectos procedimentais. A íntima e radical determinação do que seria um bem moral, para Engelhardt, revela-se, como a consciência, de cada indivíduo, mas não a uma consciência exclusiva ou específica, mas a uma em que se relacionam processos relativos a uma sensibilidade e emotividade, o que, em si, é um aspecto pós-moderno.

Nota-se, no pensamento de Engelhardt, uma nota pessimista, ao se perceber que a moralidade canônica ou universal teria fracassado, pois tal concepção secular carece de força que seria esperada na cultura ocidental, quando reconhecida, ancorada e reforçada por um Deus. Estando, assim, o Deus ausente, muda toda a apreciação da moral, seu significado metafísico, a experiência fenomenológica da mesma na realidade.

\subsection{Críticas ao pensamento de Engelhardt}

O ponto de partida do pensamento de Engelhardt é a aceitação do pluralismo em um contexto pós-moderno. Dentro destas condições, não haveria nenhuma outra alternativa do que a constituição de um espaço comum (a sociedade) para que se possa mover livremente e viver de acordo com as conviç̧ões pessoais, seja participando de uma comunidade, seja criando novas comunidades. O tecido conectivo deste espaço compartilhado por estranhos morais estaria constituído unicamente pela decisão de não se recorrer ao uso da força para resolver as controvérsias, sejam elas éticas, religiosas ou culturais.

A isto denomina-se por pluralismo estático. No modelo proposto por Engelhard, o diálogo entre os estranhos morais ocorre através de pactos, acordos ou contratos. Há indícios de que, em geral, as relações ocorram desta maneira. Porém, em outros, os dissensos são tantos e profundos que parece impossível a sua solução. Afirmar isto significaria entender que a única via para solução seria o acordo estratégico. Podem surgir diversas situações, como a possibilidade de os protagonistas das controvérsias modificarem suas posições, chegando-se a conclusões diferentes. Também, é possível que os protagonistas tentem maximizar seus objetivos, levando em consideração que possam exercer maior influência sobre seus pares ${ }^{34}$.

\footnotetext{
${ }^{33}$ MADRID, R. op. cit. p. 447

${ }^{34}$ DORDONI, P. Bioética y pluralismo: el método Socrático en la tradición de Leonard Nelson y Gustav Heckman en Medicina. 2007. 499 p. Tese (Doutorado em Filosofia) - Universidad Complutense de Madrid - Facultad de Filosofía. Acesso em: 20 nov 2018. p. 65
}

14 | Revista do Programa de Pós-Graduação em Direito da UFBA, e-issn 2358-4777, v. 30, n. 01, p.05-24, Jan-Jun 2020 
O fim do acordo é obter o máximo possível do que seria eticamente aceitável. Diante de um diálogo entre estranhos morais sobre o tema relacionado ao uso recreativo de drogas. As pessoas, neste caso, tentariam convencer os demais da validade de sua posição e a correção de seus próprios argumentos. De uma parte, então, tentarão pactuar em uma sociedade a sua posição, seja tendente a uma maior liberdade no uso, seja na sua proibição. Por outro lado, poderiam promover em comunidades morais autônomas o seu propósito, seja de utilização, seja de não utilização.

Como consequência, cada um acabaria seguindo sua própria posição, sem se poder impor qualquer uma delas. Haveria, em um cenário, um diálogo entre surdos, em que ninguém consegue entender ninguém, ou um diálogo aparente, em que as pessoas expõem suas próprias posições na forma de monólogos, sem estarem interessadas realmente quanto o que dizem as demais. Para que haveria de escutar os demais se já se saberia que os outros estariam equivocados? O outro, nestes diáologos, não apresentaria argumentos, mas apenas pretende ofender ou me impedir de fazer aquilo que ele deseja. Isto acabaria por aumentar o fator de distância das comunidades e de conflito entre as pessoas. Haveria também espaço para utilização da má-fé. Em um primeiro caso, tentar-seia instruir os demais; no segundo, corrigir o seu vício moral.

Não sendo possível alcançar seus objetivos e sendo a sociedade pluralista, restaria ao sujeito atuar de forma defensiva, que é proteger os seus interesses e defender suas posições isolando-se em uma comunidade peculiar. Engelhardt exclui, como ponto de partida, tanto a possibilidade de convencer racionalmente os demais como impor, com a autoridade, seja através da força, seja através da fé, uma determinada posição. Restaria, portanto, aceitar a diferença ${ }^{35}$.

A aceitação não implica, por si só, que as pessoas sejam irracionais ou imorais, segundo um ponto de vista particular. Se, por fim, a tolerância aos demais fosse motivada pelo reconhecimento dos limites de nosso conhecimento, especialmente quanto à incapacidade da razão de elaborar um sistema capaz de acordar a todos, seguiria latente o risco de estar legitimado impor suas opiniões sobre os demais. Em outras palavras, respeitar os demais porque ninguém pode impor sua razão, por falta de legitimidade. Este pressuposto é, ao mínimo, discutível. Pense-se, por exemplo, em alguém que verifica que um ente querido está atentando contra sua vida. Seria possível justificar o respeito devido às pessoas simplesmente a partir do reconhecimento dos limites do conhecimento de cada um? Engelhardt não rechaça a possibilidade de diálogo entre estranhos morais.

O que ele faz é negar que tais controvérsias possam ocorrer por meio da razão. A única possibilidade é que a discussão seja proveitosa, através de acordos. Certamente, os participantes devem contar com atitudes peculiares, como a de estarem dispostos a modificarem suas posições, reexaminarem suas conclusões e aceitar os limites de seus próprios pensamentos. Tal atitude não é incompatível com o reconhecimento de se pertencer a uma outra comunidade. Bem da verdade, em uma mesma comunidade existem muitas diferenças de opinião e contrates do que se parece. Quando alguém, seja um grupo, seja um indivíduo, expõe suas opiniões, entram em jogo suas premissas e convicções, assim como interesses e preocupações peculiares.

A questão que se impõe é pensar nas modalidades dialógicas alternativas às meramente contratuais ou estratégicas, como práticas de diálogo não se reduzam a monólogos, interpretações do pluralismo que não se reduzam a uma aceitação passiva dele. Engelhardt interpreta a tolerância como uma não-interferência. Porém, é muito complicado considerar a não interferência de uma forma neutra.

Os indivíduos pertencentes a uma comunidade moral viveriam em uma não-interferência como um mal menor, tendo que aceitar os demais. Isto parece mais plausível, quando se pertencer a uma comunidade moral implicar aceitar a validade de algumas regras de inferência, assumidas como premissas comuns. Seguindo tais sugestões, é possível afirmar que ainda que seja possível entender e praticar a tolerância na forma mínima de não interferência, também seria possível, pelo

${ }^{35}$ ENGELHARDT, T. Op. cit. p. 68

15 | Revista do Programa de Pós-Graduação em Direito da UFBA, e-issn 2358-4777, v. 30, n. 01, p.05-24, Jan-Jun 2020 
respeito à diferença da posição dos demais, considerar a tolerância como uma preocupação ativa frente às pessoas. Porém, a tolerância ativa traria algumas preocupações, como a limitação da possibilidade de se viver de forma distinta da mesma. Uma outra possibilidade de enfrentamento do pluralismo é aceitá-lo de forma dinâmica. porque no lugar de se favorecer a retirada de pessoas de seus grupos, deveria haver seu livre intercâmbio. Por este ângulo, as diferenças não são irresolvíveis, podendo haver um enfrentamento recíproco. Trata-se de um modelo em que a confrontação ocorreria na forma de um espaço de diálogo entre comunidades e dentro de cada uma delas.

A diferença entre estranhos e amigos morais desapareceria, porque sempre se estaria disposto à realização de um debate. O diálogo entre várias comunidades, no campo bioético, ocorre diante dos comitês de ética, que trazem uma pluralidade de perspectivas, como o pensamento de práticas dialógicas adequadas para o seu trabalho. Podem ser constituídos comitês de experts, bem como de caráter técnico, ou comitês confessionais, sendo estes últimos participantes de uma comunidade peculiar.

Um pluralismo sustentável capaz de promover diálogos abertos tem de buscar formas de incluir os cidadãos em debates, levando em conta suas limitações quanto às diversas formas de conhecimento. Porém, quais seriam as condições de possibilidade de um diálogo aberto e quais são as relações entre um diálogo aberto e o respeito a um contexto pluralista? É necessário que sejam feitas perguntas, como "entrem quem?", "como". Se há uma relação estrita entre o diálogo e o pluralismo, é verdade que as modalidades de entender e praticar o diálogo nos oferece uma possibilidade de entendê-lo. Isto se constituiria em um pluralismo sustentável.

Saliente-se que nos últimos anos, a filosofia moral tem mudado suas prioridades, vindo de uma linguagem ética para a possibilidade de aplicação de uma ética prática ou aplicada. Esta ética prática não implica apenas um sistema dedutivo, mas uma relação dialética entre a teoria e a práxis, pois ambas se enriquecem de forma recíproca e a prática está sempre pronta a redefinir e remodelar tanto as teorias como as conclusões ${ }^{36}$.

\section{A cultura e o ordenamento jurídico}

A justiça retributiva é resultado de um paradigma cultural específico. Assim, a alteração para o prisma restaurativo requer a compreensão de como o direito e a cultura podem dialogar, surgindo o convite de se revisitar uma corrente de pensamento jurídico há muito esquecida, que é o culturalismo jurídico.

Miguel Reale, em seus textos, já considerou a relevância da compreensão da cultura para um adequado tratamento jurídico. Assim, explica que um dos principais culturalistas jurídicos conhecidos, Emil Lask, assimilou componentes da fenomenologia, associado-os a uma concepção tipicamente neokantiana, tendo como influência o pensamento tanto de Rickert, como de Windelband. Também se destaca o pensamento de Edmund Husserl ${ }^{37}$.

Dentre suas construções, encontra-se utiliza-se da a teoria dos objetos de Alexis Meinong, sendo estes "aquilo que está lançado diante de", ou estruturas de predeterminação de constituição e prontos para serem atingidos pela consciência. São divididos em sensíveis (os captáveis pela

\footnotetext{
${ }^{36}$ DORDONI, P. op. cit. p. 70

${ }^{37}$ REALE, M. O direito como experiência - Introdução à Epistemologia Jurídica. São Paulo: Saraiva, 1992. 56

16 | Revista do Programa de Pós-Graduação em Direito da UFBA, e-issn 2358-4777, v. 30, n. 01, p.05-24, Jan-Jun 2020
} 
experiência e presentes no tempo-espaço), os suprassensíveis (metafísicos, além do tempo-espaço) e os não sensíveis (abstrações latentes, que apenas têm ser, mas não existência) ${ }^{38}$.

Meinong que os valores são objetos sensíveis, da categoria dos psicológicos, com realidades presentes e criadas no psiquismo. Também aceita que podem adotar perspectivas transcendentais de valores, aproximando-os de objetos ideais ${ }^{39}$.

Por seu turno, Lask alia-se à teoria dos objetos de Meinong, concebendo um quarto, o cultural, que está contido no direito. Assim, os objetos culturais estão no espaço, mas não no tempo, tendo ser e existência, também podendo assumir um enfoque metafísico ${ }^{39}$.

Lask revela-se como um realista crítico, sendo adepto do objetivismo radical, considerando que no espírito há uma constância axiológica fundamental da qual advém as valorações.

Partindo da ideia de Husserl, capta as estruturas básicas da cultura, principalmente os valores, que a norteiam teleologicamente tanto em sua constituição interna, como no exterior ${ }^{40}$.

Explica Miguel Reale que Emil Lask, partindo da antítese entre o valor e a realidade, supera o neokantismo e inclui o direito no campo da cultura.

Por outro lado, Thomas Kuhn sobre os paradigmas, aplicáveis a qualquer conhecimento científico, admite que o Direito, do Século XIX até o atual, teve três paradigmas distintos, quais sejam: 1) O da segurança da lei, típico do Estado Liberal, que pregava a primazia da lei e a completude do ordenamento jurídico, entendido como um sistema fechado, como forma de garantir a segurança jurídica e a igualdade dos sujeitos; 2) O do sistema aberto, típico do Estado Social, que determinou a adoção de cláusulas gerais aptas a manter o ordenamento jurídico em constante atualização, que, por sua vez, ficava a cargo do juiz, e responsável pela inclusão dos conceitos indeterminados, dentre os quais os que, jocosamente, nomeia de "o bando dos quatro" função social, boa-fé, ordem pública e interesse público; 3) O da fuga do juiz, paradigma atualmente experimentado ${ }^{41}$.

Sustenta que, diante do processo de aceleração histórica, os sujeitos não estão mais buscando, em regra, a intervenção estatal para a solução de seus conflitos, o que restaria comprovado pelo crescimento das formas lícitas de autocomposição dos litígios. A sociedade atual, assim, não necessitaria mais das cláusulas gerais, mas sim de normativas determinadas, baseadas nos valores constitucionais, como forma de redução dos conflitos e facilitação da solução extrajudicial dos conflitos. O "bando dos quatro" não estaria mais apto a solucionar os problemas sociais.

Assim, o direito pode ser estudado em uma tríplice perspectiva, seja como uma realidade impregnada de significações normativas objetivas, seja como um fato social (estando no objeto da sociologia jurídica, ou como valores e significações, aqui encontrando a filosofia do direito ${ }^{42}$.

\footnotetext{
${ }^{38}$ FONTES, A. R. C. A ideia do objeto em Husserl e Meinong considerada a partir da filosofia de Franz Brentano.

2007. 254 p. Tese (Programa de Pós-Graduação em Filosofia) - Instituto de Filosofia e Ciências Sociais Universidade Federal do Rio de Janeiro, Rio de Janeiro. Disponível em: <https://www.sapili.org/livros/pt/cp040422. pdf>. Acesso em: 12/01/2017. 177-190

${ }^{39}$ Ibid. p. 191.

${ }^{39}$ GUSMÃO, P. D. de. Filosofia do direito. São Paulo: Forense, 2014. 45

${ }^{40}$ LIMA, N. de O. Teoria dos valores jurídicos: o neokantismo e o pensamento de gustav radbruch. Recife: Fundação Antônio dos Santos Abranches, 2009. 45

${ }^{41}$ KUHN Thomas s. A estrutura das revoluções científicas. 5. ed. São Paulo Editora Perspectiva s.a 1997

${ }^{42}$ REALE, M. Teoria tridimensional do direito. São Paulo: Saraiva, 2010.
}

17 | Revista do Programa de Pós-Graduação em Direito da UFBA, e-issn 2358-4777, v. 30, n. 01, p.05-24, Jan-Jun 2020 


\section{Finalidades da pena}

No discurso da teoria penal contemporânea, a tese de que a justificação de sua imposição somente pode se basear em um princípio de prevenção advém de um lugar como. Por outro lado, a tese alternativa é a defesa retributiva de uma pena, que somente pode ser considerada na potestade punitiva do Estado.

Determinar a função que cabe atribuir à sanção penal é o objeto da disputa tradicional entre diversas teorias que pretendam justificar a pena. Nesta discussão, não é possível prescindir de algumas características que frequentemente vêm associadas, de modo a ocasionar um equilíbrio reflexivo que envolve até mesmo sua denominação.

Destaque-se que Mir Puig entende que não apenas os direitos fundamentais devem ser reconhecidos para os cidadãos, como também são igualmente importantes os princípios reitores da política social e econômica na proteção dos bens jurídico-penais, em que a Constituição revela a indispensabilidade da proteção de tais valores como verdadeiramente constitucionais ${ }^{43}$.

Nestes termos, o termo "pena" pode significar um gênero relacionado a todo tipo de consequência jurídica, como Hart afirma ao inferir como "definitional stop" que guiam o propósito da prática punitiva ${ }^{44}$.

Por outro lado, adotando-se uma teoria pluralista, como bem elencada por Jakobs, é impossível evitar o caráter contraditório entre a conclusão que se deve impor a diversos casos, porque a suposição funcional de critério legitimadores da sanção penal podem ser combinados, em uma teoria que necessariamente culmina em uma neutralização recíproca dos propósitos retributivos e impositivos da pena ${ }^{45}$.

$\mathrm{Na}$ formulação original da teoria de Jakobs, por prevenção geral positiva se entende o efeito comunicativo a pena possui para sua imposição, que é o restabelecimento da norma jurídica violada pelo delito ${ }^{46}$. Assim, a teoria jakobsiana revela-se como utilitarista, porque constitui somente questão de giro hermenêutico, típico de uma direção helegiana, exercendo um papel em um plano simbólico de seu significado no mundo externo.

Como bem afirma Luís Greco ${ }^{47}$, as palavras de Jakobs não podem representar todo o pensamento funcionalista, inclusive porque não há apenas um único funcionalismo, mas diversos, sobretudo o capitaneado por Roxin. Assim, tomando-se por este ângulo, a pena retributiva é rechaçada, porque a tentativa de se observar um caráter meramente preventivo na proteção de bens jurídicos muitas vezes não encontra o retorno esperado no rompimento do tecido social.

Assim, é que acaba por ganhar espaço o paradigma restaurativo, que pretende resgatar o propósito de autoconsciência e pedagógico no agente do delito, com a participação efetiva da sociedade, incluindo o próprio ofendido, que encontra novos espaços na aplicação de um olhar contemporâneo da pena.

\section{Do paradigma retributivo para o restaurativo}

\footnotetext{
${ }^{43}$ MIR PUIG, Santiago. Introducción a las bases del Derecho penal, 2a ed., Bdef, Montevideo/Buenos Aires, p. 115

${ }^{44}$ HART, H. L. A.: "Prolegomenon to the Principles of Punishment", 1968, p; 5

${ }^{45}$ JAKOBS, Günther. Sobre la teoria de la pena, pp. 12-13

${ }^{46}$ Ibid., p. 62-65.

${ }^{47}$ GRECO, Luiz. Introdução à dogmática funcionalista do delito. In: POLETTI, Ronaldo Rebello de Britto (Org.). Revista Notícia do Direito Brasileiro. Nova série. n. 7. Brasília: UnB, Faculdade de Direito, 2000. p. 307-362. p. 311

18 | Revista do Programa de Pós-Graduação em Direito da UFBA, e-issn 2358-4777, v. 30, n. 01, p.05-24, Jan-Jun 2020
} 
Existem, basicamente, duas formas de se exercer a justiça criminal, conforme o atendimento das concepções teóricas: o exercício do jus puniendi através da justiça retributiva e o uso da justiça restaurativa ${ }^{48}$.

$\mathrm{Na}$ justiça retributiva há um tratamento estritamente jurídico do crime; por assim dizer, trata-se da violação da lei penal, que é exercício do monopólio estatal da justiça criminal. Entretanto, como bem aponta Guilherme Costa Câmara, a justiça retributiva já aponta sinais de desgaste. Em suas palavras:

Atualmente, não há margem para dúvida, o princípio em causa esgotou sua contribuição, ou seja, não mais representa qualquer avanço, mas simboliza lamentável retrocesso que algumas ordens jurídicas insistem em patrocinar, em verdadeira contramarcha à evolução do direito penal (do iluminismo criminal até as mais recentes proposições da política criminal, que se quer coerente com os direitos humanos cristalizados nas Cartas Fundamentais dos modernos Estados democráticos de Direito, sobremodo quando infligem - a despeito de proclamarem irrestrita obediência a esses direitos - a pena capital para crimes mais graves $^{49}$.

Explicam Selma Pereira de Santana e Carlos Alberto Miranda Santos que o discurso de combate ao crime acaba por ocasionar a exclusão social e a violação aos direitos humanos, baseando-se no paradigma da reação social ${ }^{50}$.

Salienta Leonardo Sica que mesmo a justiça penal formal deve priorizar mecanismos de intervenção que possibilitem o convívio comunitário, oferecendo modelos comportamentais que agreguem consenso ao redor das regras do ordenamento e a mensagem dos preceitos penais ${ }^{51}$.

Por outro lado, com a justiça restaurativa, o crime é concebido por um ponto de vista mais amplo, sendo considerado um ato que afeta não apenas a própria vítima, mas o infrator e a própria comunidade, provocando uma série de danos. Trata-se, portanto, de uma justiça criminal participativa $^{52}$.

Quanto ao procedimento, a justiça retributiva desenvolve-se por meio da jurisdição contenciosa, através do exercício do contraditório. Utiliza a linguagem e procedimentos formais, é um ritual solene e público, marcado - comumente - pela indisponibilidade da ação penal. Quanto aos seus personagens principais, encontram-se as autoridades, a exemplo do delegado de polícia, o membro do Ministério Público, o juiz, o advogado e demais profissionais auxiliares da Justiça.

Por outro lado, a justiça restaurativa se caracteriza por um ritual informal e comunitário, no qual participam as pessoas implicadas voluntariamente, colaborando de forma confidencial. $O$

${ }^{48}$ ALENCAR, V. E. La Justicia Restaurativa Brasileña. Revista Jurídica, Unievangelica, Anápolis/GO, v. 18, n. 1, p. 38 55, 2011. ISSN 2236-5788. Disponível em: <http://periodicos.unievangelica.edu.br/index.php/revistajuridica/ article/view/3011>. Acesso em: 20 abr 2018. 51

${ }^{49}$ CÂMARA, G. C. Programa de Política Criminal Orientado para a Vítima do Crime. São Paulo: Revista dos Tribunais, 2008. p. 29

${ }^{50}$ SANTANA, S. P. de; SANTOS, C. A. M. A justiça restaurativa como política pública alternativa ao encarceramento em massa. Revista Brasileira de Políticas Públicas, UniCeub, Brasília, v. 8, n. 1, p. 228 - 242, Abril 2018. ISSN 2236-1677. Disponível em <https://www.publicacoesacademicas.uniceub.br/RBPP/article/viewFile/5059/3678>. Acesso em: 02/12/2018. p. 230

${ }^{51}$ SICA, L. Justiça Restaurativa e Mediação Penal. O novo modelo de justiça criminal e de gestão do crime. Rio de Janeiro: Lumen Juris, 2007. p.5

${ }^{52}$ ALENCAR, op. cit., p. 42

19 | Revista do Programa de Pós-Graduação em Direito da UFBA, e-issn 2358-4777, v. 30, n. 01, p.05-24, Jan-Jun 2020 
protagonista é a vítima, ao lado dos infratores e da própria comunidade. Quanto ao poder de decisão, este é compartilhado entre as autoridades formais e os implicados, caracterizando-se verdadeira multidimensionalidade ${ }^{53}$.

Com relação às consequências que afetam às vítimas, a justiça retributiva não se mostra tão eficaz, praticamente excluindo-a do processo, tornando-a um meio de prova. Por outro lado, na justiça restaurativa, a vítima se ocupa de uma posição praticamente central, pois possui participação e controle sobre os atos que lhe afetam.

$\mathrm{Na}$ justiça retributiva o infrator tem sua participação restringida, inclusive pelo direito constitucional à ampla defesa manifestado pelo silêncio. Por outro lado, na justiça restaurativa há um enquadramento do ofensor como alguém que deve se responsabilizar pelos danos causados pelo delito, porém de forma integrada à satisfação da vítima e à integração com a comunidade, pois ambas participam do processo.

A justiça restaurativa se afasta de um dos pontos em que normalmente há maior incidência da intervenção penal: o crime em si, a reação social e o delinquente. Seu objetivo, não obstante, foca-se nas consequências do crime e as relações sociais que se veem afetadas pela conduta penal.

O crime é um conflito entre indivíduos que afeta uma ou várias vítimas, ou ainda a própria comunidade, podendo também ter consequências sobre o próprio autor. Ademais, em muitos casos, faz-se necessário um abrandamento da lei penal, pois o objetivo da justiça criminal deve ser reconciliar pessoas e reparar os danos causados pelo crime, assim como proporcionar a cooperação entre as vítimas, os autores dos fatos e suas comunidades.

Como proposta de procedimento, a justiça restaurativa pode ter início na própria delegacia de polícia, na qual o delegado e seus agentes selecionariam casos elegíveis para aplicação da justiça restaurativa.

Em seguida, um promotor e um magistrado, tendo recebido os termos detalhados da ocorrência, podem propor às partes uma audiência preambular de participação de círculos restaurativos. Aceitando as partes, o processo deverá ser suspenso até que seja finalizado os círculos. Havendo consenso, dentro dos limites legais, o acordo deverá ser homologado, arquivando-se o caso.

Desta forma, o procedimento se iniciação por se colocar em contato o infrator e sua vítima, de modo a possibilitar sua participação. Aplica-se a realização dos círculos restaurativos entre as partes, em que não participariam nem o membro do Ministério Público e nem o magistrado. Aberto o procedimento, busca-se, de melhor forma possível, a promoção do acordo entre as partes, dentro do marco da legalidade. O encontro entre os envolvidos será moderado por um facilitador, que seguirá pautas pré-determinadas e se desenvolve em um espaço adequado, que assegure a proteção dos envolvidos para a solução do conflito ${ }^{54}$.

\subsection{Pré-círculo}

Trata-se da preparação dos participantes. Consiste em uma fase preparatória, para a posterior participação do círculo restaurativo. Nesta fase, o facilitador estabelece o primeiro

\footnotetext{
${ }^{53}$ SICA, L. Justiça Restaurativa e Mediação Penal. O novo modelo de justiça criminal e de gestão do crime. Rio de Janeiro: Lumen Juris, 2007. 55

${ }^{54}$ SICA, L. Justiça Restaurativa e Mediação Penal. O novo modelo de justiça criminal e de gestão do crime. Rio de Janeiro: Lumen Juris, 2007. p. 98
}

20 | Revista do Programa de Pós-Graduação em Direito da UFBA, e-issn 2358-4777, v. 30, n. 01, p.05-24, Jan-Jun 2020 
contato com o autor, o receptor e a comunidade em separado, de modo a obter três versões, bem como os fatos e as consequências ${ }^{55}$.

Em seguida, são esclarecidas as etapas do procedimento restaurativo, bem como são colhidas as manifestações de vontade para posterior participação no círculo restaurativo. 0 propósito deste processo é possibilitar que o círculo seja objetivo, evitando desgastes desnecessários entre os participantes.

Trata-se de uma fase essencial para o progresso do procedimento, uma vez que o recebimento da informação pelo facilitador por parte de cada um dos participantes Ihe permitirá estabelecer os passos a seguir durante as próximas etapas do círculo restaurativo, inclusive para que que o infrator admita sua conduta.

\subsection{0 círculo}

Durante o círculo ocorrerá o encontro propriamente dito entre os envolvidos. O mesmo é iniciado pelo facilitador, que explica a todos a estrutura que se seguirá quanto ao procedimento, fazendo referências ao conteúdo do termo de consentimento, que firmarão todos os participantes ${ }^{56}$.

O próprio círculo é composto por três fases:

a) Compreensão mútua e enfoque a partir das necessidades atuais;

b) Auto responsabilização;

c) Acordo para atendimento das necessidades.

A primeira fase centra-se nas necessidades atuais dos envolvidos. Através do diálogo, expressam seus sentimentos e relatam como poderiam obter uma compreensão mútua de suas necessidades atuais. Além disto, os implicados diretos da comunidade também se manifestam ao final do acordo.

$\mathrm{Na}$ segunda etapa, as necessidades ganham maior protagonismo, em que os participantes revisam os atos e assumem auto responsabilização perante os presentes.

$\mathrm{Na}$ última fase, delineiam-se as necessidades de que necessitam ser solucionadas e a orientação acerca do acordo. É neste momento que surge a necessidade de se transformar o conflito, mediante o estabelecimento de metas para que os participantes se comprometam a cumprir, em determinado prazo.

Se o encontro se revela viável, o profissional da equipe técnica citará a vítima, o menor infrator e seu representante legal, para que então seja iniciada a mediação. No encontro, visa-se eliminar possíveis tensões, de modo a fixar as condições para a mediação.

Embora seja indicada a proposta de reparação material, admite-se a reparação simbólica, especialmente para os casos em que o delito não tem vítima pré-determinada, ou que não pôde ser identificada.

\subsection{0 pós-círculo}

\footnotetext{
${ }^{55}$ ALENCAR, V. E. op. cit. p. 45

${ }^{56}$ Ibid. p. 46
}

21 | Revista do Programa de Pós-Graduação em Direito da UFBA, e-issn 2358-4777, v. 30, n. 01, p.05-24, Jan-Jun 2020 
O pós-círculo é caracterizado pelo acompanhamento do acordo firmado. Nesta fase final, reúnem-se os implicados, incluindo os participantes da execução das metas constantes no acordo, para comprovar o cumprimento do mesmo, verificando se o acordo fora satisfatório ou não para todos, sendo possível a propositura de novos projetos. Admite-se o diálogo como ferramenta mediadora também para esta etapa ${ }^{57}$.

O acordo restaurativo deve estabelecer claramente quem são os responsáveis e quais são os compromissos que devem assumir diante do pacto acordado, que normalmente - mas não obrigatoriamente - deve ser feito imediatamente. Durante o período em que serão compensados os danos, o facilitador estará em contato com ambas as partes, para assegurar seu cumprimento, bem como facilitar algum possível inconveniente.

Havendo eventual descumprimento do acordo, deverá constar um informe quanto a isto. A solução deve ser avaliada caso a caso com os participantes, de modo a evitar a quebra de todo o combinado. A depender do grau de descumprimento, uma das três soluções poderá ser proposta:

a) Realização de um novo círculo restaurativo;

b) Realização de um círculo familiar;

c) Soluções convencionais pela justiça forma ${ }^{58}$.

Verifica-se, desta forma, que a justiça restaurativa não visa provocar nem o abolicionismo penal, muito menos se afastar da justiça formal. Reconhece-se a autonomia das partes, de modo que os acordos têm o seu cumprimento assegurado pelo suporte da justiça formal, que nunca deixa de estar à disposição para aplicação do poder de império estatal.

\section{Considerações finais}

Através do presente trabalho, buscou-se identificar alguns fundamentos éticos e filosóficos que tenham por propósito colaborar para uma aplicação mais segura da justiça restaurativa.

Nota-se que o paradigma de uma justiça restaurativa encontra bases no próprio pensamento humano culturalista e ético, que apenas necessita ser resgatado, dada a impossibilidade de se estabelecer uma única resposta formal segura para os diversos conflitos sociais, havendo a necessidade de que as partes, com seus valores, possam se tornar protagonistas deste processo.

Houve especial destaque à obra de Tristam Engelhardt, que ceifou, em seu pensamento, a ideia de que pudesse existir um único paradigma moral e, frente à diversidade, as pessoas necessitam dialogar.

É possível compreender na obra de Engelhardt como um dos últimos esforços para restabelecer a possibilidade de uma ética global em um universo moral que inicia o reconhecimento e aceitação da diversidade e do multiculturalismo. A proposta é intrinsecamente formal e acaba por se revelar muitas vezes contraditória com as crenças pessoais do autor, um católico ortodoxo.

A possibilidade de contradição, por outro lado, reforça no pensamento de Engelhardt para explicar a situação moral, demonstra a influência de elementos pós-modernos, que provavelmente operam de modo inconsciente, junto com outros elementos de autores contratualistas e comunitaristas.

\footnotetext{
${ }^{57}$ Op. Cit. p. 47

${ }^{58}$ Op. cit. p. 53
}

22 | Revista do Programa de Pós-Graduação em Direito da UFBA, e-issn 2358-4777, v. 30, n. 01, p.05-24, Jan-Jun 2020 
Tal variedade de pressupostos reafirma a ideia de que Engelhardt não é tão um filósofo abstrato da ação moral, mas sim um acadêmico que tenta resolver problemas concretos da bioética, campo no qual sua contribuição se relevou bastante relevante.

Logo, a justiça restaurativa acaba por se revelar um caminho mais legítimo para o enfrentamento dos conflitos, especialmente os penais, atuando em paralelo à justiça formal, com a qual dialoga e mantém relação de equilíbrio.

Através da justiça restaurativa, ocorre a aproximação dos sujeitos envolvidos, ao contrário do que ocorre nos casos do processo judicial tradicional. Assim, o objetivo da justiça restaurativa é a consequência do crime e das relações sociais afetadas pela conduta. Logo, não adianta a mera realização do acordo, mas o restabelecimento das relações sociais afetadas.

\section{Referências}

ALENCAR, V. E. La Justicia Restaurativa Brasileña. Revista Jurídica Unievangelica, Anápolis/GO, v. 18, n. 1 , p. $38-55,2011$. ISSN 2236-5788. Disponível em: <http:

//periodicos.unievangelica.edu.br/index.php/revistajuridica/article/view/3011>. Acesso em: 20 abr 2018.

CÂMARA, G. C. Programa de Política Criminal Orientado para a Vítima do Crime. São Paulo: Revista dos Tribunais, 2008.

CARDO, J. L. Lévinas - El sujeto debe responsabilizarse de los otros hasta el punto de renunciar a sí mismo. Barcelona: RBA Contenidos Editoriales y Audiovisuales, 2015.

CHALIER, C. Por una moral más allá del saber. Kant y Lévinas. Madri: Caparrós, 2002.

DAVIS, C. Levinas - An Introduction. Indiana - EUA: University of Notre Dame Press, 1996.

DORDONI, P. Bioética y pluralismo: el método Socrático en la tradición de Leonard

Nelson y Gustav Heckman en Medicina. 2007. 499 p. Tese (Doutorado em Filosofia) Universidad Complutense de Madrid - Facultad de Filosofía. Acesso em: 20 nov 2018.

ENGELHARDT, J. H. T. Fundamentos da Bioética. 5. ed. São Paulo: Edições Loyola, 2013.

FONTES, A. R. C. A ideia do objeto em Husserl e Meinong considerada a partir da filosofia de Franz Brentano. 2007. 254 p. Tese (Programa de Pós-Graduação em Filosofia) - Instituto de Filosofia e Ciências Sociais - Universidade Federal do Rio de Janeiro, Rio de Janeiro. Disponível em: <https://www.sapili.org/livros/pt/cp040422.pdf>. Acesso em: 12/01/2017.

GRECO, Luíz. Introdução à dogmática funcionalista do delito. In: POLETTI, Ronaldo Rebello de Britto (Org.). Revista Notícia do Direito Brasileiro. Nova série. n. 7. Brasília: UnB, Faculdade de Direito, 2000. p. 307-362. p. 322

GUSMÃO, P. D. de. Filosofia do direito. São Paulo: Forense, 2014.

HART, H. L. A.: Prolegomenon to the Principles of Punishment, 1968, in HART, H. L. A: Punishment and Responsibility. Oxford: Clarendon Press, 1968.

KUHN Thomas s. A estrutura das revoluções científicas. 5. ed. São Paulo Editora Perspectiva s.a 1997 
JAKOBS, Günther. Sobre la teoria de la pena. Bogotá: Universidad Externado de Colombia, 1998. LÉVINAS, E. Autrement qu'être ou au-dela de l'essence. Haia: The Hague: Martinus Nihjoff, 1978.

LÉVINAS, E. Totalidade e infinito. Lisboa: Edições 70, 2008.

LIMA, N. de O. Teoria dos valores jurídicos: o neokantismo e o pensamento de Gustav Radbruch. Recife: Fundação Antônio dos Santos Abranches, 2009.

MADRID, R. La bioética de Tristram Engelhardt: entre la contradicción y la postmodernidad. Revista Bioética, Pontificia Universidad Católica de Chile, Santiago, v. 22, n. 3, p. 441

- 447, 2014. Disponível em: <http://www.scielo.br/scielo.php?script=sci_arttext\&pid= S198380422014000300007\&lng=es\&tlng=es>. Acesso em: 25 nov 2018.

PALACIO, M. La vulnerabilidad fundando lá ética de la solidaridad y la justicia. Análisis. Revista de Investigación filosófica, v. 2, n. 1, p. 29 -47, 2015.

MIR PUIG, Santiago. Introducción a las bases del Derecho penal, 2a ed., Bdef, Montevideo/Buenos Aires

REALE, M. O direito como experiência - Introdução à Epistemologia Jurídica. São Paulo: Saraiva, 1992.

REALE, M. Teoria tridimensional do direito. São Paulo: Saraiva, 2010.

SANTANA, S. P. de; SANTOS, C. A. M. A justiça restaurativa como política pública alternativa ao encarceramento em massa. Revista Brasileira de Políticas Públicas, UniCeub, Brasília, v. 8, n. 1, p. 228 - 242, Abril 2018. ISSN 2236-1677. Disponível em:

$<$ https://www.publicacoesacademicas.uniceub.br/RBPP/article/viewFile/5059/3678>. Acesso em: 02/12/2018.

SICA, L. Justiça Restaurativa e Mediação Penal. O novo modelo de justiça criminal e de gestão do crime. Rio de Janeiro: Lumen Juris, 2007 